\title{
Editorial: Plant Responses to Phytophagous Mites/Thrips and Search for Resistance
}

\author{
Raul A. Sperotto ${ }^{1 *}$, Vojislava Grbic ${ }^{2 *}$, Maria L. Pappas ${ }^{3 *}$, Kirsten A. Leiss ${ }^{4 *}$, \\ Merijn R. Kant ${ }^{5 *}$, Calum R. Wilson ${ }^{6 *}$, M. Estrella Santamaria ${ }^{7 *}$ and Yulin Gao ${ }^{8 *}$ \\ ${ }^{1}$ Graduate Program in Biotechnology, University of Taquari Valley-Univates, Lajeado, Brazil, ${ }^{2}$ Department of Biology, \\ University of Western Ontario, London, ON, Canada, ${ }^{3}$ Department of Agricultural Development, Democritus University of \\ Thrace, Orestiada, Greece, ${ }^{4}$ Horticulture, Wageningen University \& Research, Wageningen, Netherlands, ${ }^{5}$ Department of \\ Evolutionary and Population Biology, Institute for Biodiversity and Ecosystem Dynamics, University of Amsterdam, \\ Amsterdam, Netherlands, ${ }^{6}$ Tasmanian Institute of Agriculture, University of Tasmania, Hobart, TAS, Australia, ${ }^{7}$ Centro de \\ Biotecnología y Genómica de Plantas, Instituto Nacional de Investigación y Tecnología Agraria y Alimentaria, Universidad \\ Politécnica de Madrid, Madrid, Spain, ${ }^{8}$ State Key Laboratory for Biology of Plant Diseases and Insect Pests, Institute of Plant \\ Protection, Chinese Academy of Agricultural Sciences, Beijing, China
}

Keywords: mites, thrips, plant responses, defense, resistance, tolerance

\section{Editorial on the Research Topic}

\section{Plant Responses to Phytophagous Mites/Thrips and Search for Resistance}

Phytophagous mites and thrips are global pests affecting a wide range of agricultural crops (Mouden et al., 2017; Agut et al., 2018). Among the arthropods, they are phylogenetically distant, but both classes harbor species ranging from highly specialized to extremely polyphagous (Rioja et al., 2017; Wu et al., 2018). Through convergent evolution, mites and thrips evolved stylets to facilitate feeding from mesophyll or epidermal cells (Bensoussan et al., 2016; Rioja et al., 2017; Wu et al., 2018). Despite large crops losses (Agut et al., 2018; Steenbergen et al., 2018) that are expected to become more severe with global warming (Ximenez-Embún et al., 2017; Urbaneja-Bernat et al., 2019), the interactions between mites/thrips and their host plants have been understudied. Hence, understanding how plants defend themselves against these pests is essential for developing crop protection strategies. This Research Topic provides an update on recent advances in the plant molecular and physiological mechanisms associated with phytophagous mite/thrips-plant interactions, and provides an overview of different approaches for improving crop resistance sustainably, either through repellence, feeding disruption or prevention of feeding damage. Here, we highlight some of the major points arising from these reports.

\section{MITE-RELATED}

\section{Plant Resistance}

The ability of zoophytophagous predators such as the mirid Macrolophys pygmaeus to induce plant defenses and indirectly affect spider mites is well-known (Pappas et al., 2015; Zhang et al., 2018). Recently, Cruz-Miralles et al. (2019) showed that Euseius stipulatus, a zoophytophagous phytoseiid common in citrus, can trigger plant-genotype specific defensive responses and affect their prey beyond predation through plant-mediated effects. In this topic, Pérez-Hedo et al. report reduced infestation of tomato plants exposed to the mirid predator Nesidiocoris tenuis by the spider mite Tetranychus urticae. This effect correlated with the upregulated expression of a jasmonic acidresponsive gene (PIN2) and two protease inhibitors markers (PI-II1 and PI-II2) in tomato plants, indicating that crop protective benefits of zoophytophagous predators include both herbivore predation and the induction of plant innate defenses. Furthermore, the negative correlation of 
the zingiberene content of tomato trichomes and spider mite performance was described by de Oliveira et al. demonstrating a multifaceted role of this terpene in defense response. Glandular trichomes and zingiberene contribute greatly to the resistance of wild tomatoes against herbivores (Glas et al., 2012). The ability to accumulate zingiberene in glandular trichomes is being transferred to commercial varieties to increase resistance to mites and whiteflies (Bleeker et al., 2012).

The red spider mite, Tetranychus neocaledonicus, can be an important pest on lima bean (Phaseolus lunatus) (Gomes Neto et al., 2017). de França et al. assessed antibiosis and antixenosis effects of nine lima bean genotypes against the red spider mite and identified two distinct groups. The authors propose that one set of these genotypes can be used in trap cropping strategies, and the second can be used as a source of resistance against T. neocaledonicus.

T. urticae genome contains a large number of cysteineand serine-proteases, indicating their importance in spider mite physiology (Santamaria et al., 2015). However, cystatins and serine-protease inhibitors are plant defense proteins that target these mite proteins (Santamaria et al., 2012; Martel et al., 2015). Arnaiz et al. investigated the role of Arabidopsis Kunitz Trypsin Inhibitors (KTI) on plant defense against spider mite and showed that KTI confer resistance to T. urticae. Moreover, transient overexpression of KTI4 and KTI5 in tobacco demonstrated their bifunctional ability to inhibit cysteine- and serine-proteases. It is expected that KTI impact mite gut cysteine-proteases involved in the hydrolysis of dietary proteins and can thus be used as a potential tool to engineer plant resistance/tolerance to T. urticae.

Monocots, including grasses, are attacked by generalist and specialist herbivores. Several spider mite species are key pests on cereals, including the generalist T. urticae (Grbić et al., 2011) and the Poaceae specialist Oligonychus pratensis (Bynum et al., 2015). Bui et al. provided evidence that maize and barley defenses induced by $T$. urticae and $O$. pratensis herbivory are similar. However, a functional benzoxazinoid pathway negatively affected only the performance of the generalist $T$. urticae and not the specialist $O$. pratensis, suggesting that $O$. pratensis adapted to the maize as a plant-host by evading benzoxazinoid defenses. Similarly, Arena et al. used RNAseq to assess the global response of Arabidopsis upon the infestation of the false spider mite Brevipalpus yothersi. Brevipalpus feeding induced jasmonic acid (JA)- and salicylic acid (SA)-regulated Arabidopsis responses, very similar to those resulting from T. urticae feeding (Zhurov et al., 2014). However, Arena et al. demonstrated that Arabidopsis defenses affect Brevipalpus differently than T. urticae, since Brevipalpus is insensitive to JA-regulated defenses, and requires the SA pathway for maximal performance. The comparative analysis of mechanisms underlying differential responses of $T$. urticae, O. pratensis, and Brevipalpus to plant defenses will provide new insights into mechanisms of mite adaptation to different host plants.

The phytohormones gibberellic acid (GA) and JA regulate plant growth/development and defense, respectively (Hou et al., 2013). Several studies have addressed the plant dilemma between "to grow" and "to defend" in response to various stimuli, indicating that plants prioritize GA- or JA-induced responses
(Heinrich et al., 2013; Qin et al., 2013; De Bruyne et al., 2014; Wang et al., 2015; Campos et al., 2016; Guo et al., 2018). Sperotto et al. observed that wild rice species are highly susceptible to the mite Schizotetranychus oryzae. This was possibly due to a high GA:JA ratio, since the tested wild species are relatively tall $(1.5-5 \mathrm{~m})$. Therefore, authors suggest the use of short and stocky Oryza species as primary sources of mite resistance.

While resistance is aimed at maximizing plant fitness by targeting herbivores, other traits may maximize fitness through compensatory physiological responses (Koch et al., 2016; Erb, 2018), while tolerating the herbivore. Very little is known about the genetic mechanisms of tolerance (Peterson et al., 2017). In an Opinion article, Sperotto et al. reason that crops are tolerant when they produce acceptable yields and maintain fitness when infested. By evaluating rice morphology and productivity, Buffon et al. subsequently identified a rice cultivar tolerant to S. oryzae. Together they argue that tolerance, as a mechanism for maximizing yield and productivity, should be more at the forefront of crop protection research, since this is what really matters to farmers.

\section{Responses to Mixed Stimuli}

Plants are exposed to numerous biotic and abiotic stresses. To survive these challenges they have to undergo distinct physiological and structural transformations that can be costly (Wang et al., 2003). Plant responses to abiotic stress may also affect the performance of herbivores (Scheirs et al., 2006). Some plants evolved the ability to accumulate heavy metals from the soil in their shoots. It was suggested that this can provide protection against herbivores (Boyd, 2007; Hörger et al., 2013). Godinho et al. showed that tomato plants can accumulate cadmium (Cd) to levels that negatively affect spider mite performance, while not affecting the plant. They observed detrimental $\mathrm{Cd}$ effects on mites, regardless of their ability to induce or suppress plant defenses. This suggests that $\mathrm{Cd}$-accumulation could provide a plastic plant resistance trait that can also counteract defense-suppression by herbivores. Furthermore, the study of Tetranychus evansi performance on drought-adapted tomatoes showed a positive link between the induction of soluble carbohydrates and amino acids used by the plant for osmotic adjustment during drought and mite performance (Ximénez-Embún et al.). Tetranychus evansi downregulated the accumulation of defenserelated phytohormones in control and drought-adapted plants, indicating that drought promotes T. evansi tomato infestation.

Beneficial microorganisms are known to promote plant growth and confer resistance to biotic and abiotic stressors (Pieterse et al., 2014; Finkel et al., 2017). Pappas et al. studied the effect of a beneficial endophytic fungus (Fusarium solani, FsK) on tomato defenses against T. urticae, and showed that both direct and indirect defenses can be enhanced on endophyte-colonized plants. Defense-related genes were differentially expressed and $T$. urticae performance was negatively affected by FsK-colonization. Furthermore, FsK-colonized plants emitted different volatiles in response to T. urticae compared to control plants, and were more attractive to Macrolophus pygmaeus, a natural enemy of spider mites. Therefore, three-way interactions (such as tomato-FsK-T. 
urticae) may offer the opportunity for the development of novel tools for spider mite control.

Wheat curl mite (WCM), Aceria tosichella, is a major pest of wheat that vectors damaging plant viruses (Navia et al., 2013). Skoracka et al. reviewed the current knowledge on WCM-wheatvirus interactions and identified gaps in underlying mechanisms of mite infestation, viral epidemiology, and plant responses. They emphasize the application of molecular techniques in mite-wheat-virus studies and discuss the possibilities for breeding cereal cultivars carrying resistance genes against WCM and viruses.

\section{Modulation of Plant Defense Response}

Some herbivores evolved the ability to counteract plant defenses by producing effectors that disrupt plant signaling and induce effector-triggered susceptibility (Hogenhout and Bos, 2011; Ferrari et al., 2013; Pel and Pieterse, 2013). Accordingly, several species of spider mites were shown to suppress plant defenses (Kant et al., 2008) via effectors (Villarroel et al., 2016). While under laboratory conditions this can promote mite performance, it can also encourage competition and predation (Ataide et al., 2016). Blaazer et al. asked why the suppression trait is common among mites and argue that buffering traits may shield it from natural selection. Thus, mites in nature may have to work hard to limit the ecological costs associated with suppression and to keep a monopoly on their feeding site.

\section{Others (Digestive System of Tetranychus urticae and Eriophyoid Mites)}

Plants evolved several strategies to deter herbivory. These traits, in turn, have selected for counter-adaptations in herbviores to cope with plant defenses (Heidel-Fischer and Vogel, 2015). The wide host range of $T$. urticae suggests that it may have evolved general traits that allow digestion and detoxification of a wide range of different plant compounds (Rioja et al., 2017). Bensoussan et al. described the organization and properties of T. urticae alimentary system, as well as the functional properties of digestive compartments relative to their ability to parcel out molecules of different weights. Together with genomic and reverse genetics tools, this will enable a functional dissection of the T. urticae gut to identify the specific features that enabled the evolution of T. urticae extreme generalist feeding strategy.

Eriophyoid mites are extremely small phytophagous arthropods with unusual morphological, biological and behavioral specialization compared to other Acari (Skoracka et al., 2010). Many of them are major plant pests, and some increase their impact by transmitting plant viruses (Stenger et al., 2016; Skoracka et al.). De Lillo et al. reviewed current knowledge on agriculturally relevant eriophyoids with emphasis on sources for host plant resistance. This review aims to guide future efforts for achieving basic, specific, and applied goals in plant protection against these mites.

\section{THRIPS-RELATED}

\section{Plant Resistance}

Constitutive resistance to thrips across all plant life stages is essential for more sustainable and successful cultivation of
Capsicum (Ssemwogerere et al., 2013). Visschers et al. screened 40 Capsicum accessions for resistance to Frankienella occidentalis and Thrips tabaci over the plant's ontogenetic development by measuring leaf damage. Results show that resistance in Capsicum is species-specific and its levels determined by the plant's developmental stage, suggesting that breeding for resistance should not rely on screening in only one ontogenetic stage.

Thrips are also major pests of peanut worldwide and serve as vectors of devastating orthotospoviruses (Riley et al., 2011). Srinivasan et al. describe field resistance to different thrips species in peanut based on morphological or chemical traits. They also discuss screening methods, marker-assisted selection and genetic modifications that can be integrated to manage thrips and associated viruses, and layout future directions in peanut thrips management.

Some thrips species can induce gall formation, thereby altering the development of host tissues (Hori, 1992). Galls are obtained via manipulation of the host's cellular communication system and often include suppression of defenses (Oates et al., 2016). Jorge et al. studied structural and chemical changes in Myrcia splendens plants associated with galls induced by Nexothrips sp. Major structural changes during gall formation included alteration of the number and size of oil glands, which could affect leaf volatile production. Comparing the headspace volatiles, over 80 different compounds were differentially detected. It was concluded that presence of methyl salicylate in non-galled samples may be a bioindicator for host resistance.

\section{Responses to Mixed Stimuli (Induced Resistance Against Thrips)}

Fungal endophytes may prime plant defenses resulting in a stronger and/or faster response to attack by herbivores (Brotman et al., 2010). Muvea et al. demonstrated that colonization with the endophyte Hypocrea lixii plays an important role in mediating induced resistance to Thrips tabaci in onion. Plants colonized with the endophyte showed substantially decreased thrips feeding activity, as well as reduced replication of Iris yellow spot virus (IYSV), resulting in decreased disease incidence.

Inducible plant defense against western flower thrips (WFT) have recently been proposed as a promising tool for thrips control (Steenbergen et al., 2018). Chen et al. showed that Pseudomonas syringae pv. tomato DC3000 (Pst) activates the JA signaling pathway through the production of phytotoxin coronatine (COR). Infection of tomato plants with non-pathogenic concentrations of Pst or spray treatments with COR led to significant reduction of WFT feeding damage.

\section{New Technologies for Recording and Analysis of Insect Behavior}

The search for genetic resistance against thrips has been ongoing for a long time (Douglas, 2018). However, the toolbox for studying genetic resistance to thrips is limited. Abd-El-Haliem et al. present a method for the identification of genes relevant to thrips performance. They utilized an Agrobacterium tumefaciensmediated expression of candidate thrips genes within leaf discs 
of the target host on which subsequently thrips performance was assessed. The methodology allows for testing of multiple candidate genes without the need for production of stable transformed plants.

Host-plant resistance to insects, like thrips, is a complex trait difficult to phenotype quickly and reliably. A crucial element is the accurate estimation of resistance level, which requires robust phenotyping systems that can accurately screen many different plant lines in a high-throughput manner (Kloth et al., 2012; Goggin et al., 2015). Jongsma et al. introduce novel hardware and software to facilitate insect choice-assays and to automate the acquisition and analysis of movement tracks. The analysis resulted in much larger contrasts in behavior traits than previously reported. Compared to leaf damage assays on whole plants or detached leaves, this method is faster and more reliable than previous methods.

\section{MITE/THRIPS-RELATED}

There are indications that plant responses against herbivores may be influenced by bacteria associated with herbviores (Chung et al., 2013; Su et al., 2015). Schausberger discussed the abundance and diversity of bacteria associated with spider mites and thrips, and argued that these can have a profound impact on herbivoreinduced plant defense responses. Gut/saliva-associated and endosymbiotic bacteria introduced into plants during feeding can induce plant defenses, such as the activation of SA pathway, which decreases the expression of JA pathway. Schausberger stressed there is need for further research to pinpoint the effects

\section{REFERENCES}

Agut, B., Pastor, V., Jaques, J. A., and Flors, V. (2018). Can plant defence mechanisms provide new approaches for the sustainable control of the Two-Spotted Spider Mite Tetranychus urticae? Int. J. Mol. Sci. 19:614. doi: $10.3390 /$ ijms19020614

Ataide, L. M. S., Pappas, M. L., Schimmel, B. C. J., Alba, J. M., Orenes, A., Janssen, A., et al. (2016). Induced plant-defenses suppress herbivore reproduction but also constrain predation of their offspring. Plant Sci. 252, 300-310. doi: 10.1016/j.plantsci.2016.08.004

Bensoussan, N., Santamaria, M. E., Zhurov, V., Diaz, I., Grbić M., and Grbić V. (2016). Plant-herbivore interaction: dissection of the cellular pattern of Tetranychus urticae feeding on the host plant. Front. Plant Sci. 7:1105. doi: $10.3389 /$ fpls.2016.01105

Bleeker, P. M., Mirabella, R., Diergaarde, P. J., vanDoorn, A., Tissier, A., Kant, M. R., et al. (2012). Improved herbivore resistance in cultivated tomato with the sesquiterpene biosynthetic pathway from a wild relative. Proc. Natl. Acad. Sci. U.S.A. 109, 20124-20129. doi: 10.1073/pnas. 1208756109

Boyd, R. S. (2007). The defense hypothesis of elemental hyperaccumulation: status, challenges and new directions. Plant Soil 293, 153-176. doi: 10.1007/s11104-007-9240-6

Brotman, Y., Kapuganti, J. G., and Viterbo, S. (2010). Trichoderma. Curr. Biol. 20, 390-391. doi: 10.1016/j.cub.2010.02.042

Bynum, E. D., Michels, J., MacDonald, J. C., and Bible, J. B. (2015). Impact of Banks grass mite damage to yield and quality of maize silage. Southwest. Entomol. 40, 251-262. doi: 10.3958/059.040.0202

Campos, M. L., Yoshida, Y., Major, I. T., de Oliveira Ferreira, D., Weraduwage, S. M., Froehlich, J. E., et al. (2016). Rewiring of jasmonate and phytochrome that different bacterial groups - and their elicitors - have on plant defense against mites and thrips.

\section{FINAL COMMENT}

In summary, the work presented here documents recent advances in the interface between plants and mites or thrips. Now, the challenge is to move forward, to integrate this information and to develop knowledge-driven sustainable control strategies against a diverse range of mite and thrips pests.

\section{AUTHOR CONTRIBUTIONS}

All authors listed have made a substantial, direct and intellectual contribution to the work, and approved it for publication.

\section{FUNDING}

RS was supported by Conselho Nacional de Desenvolvimento Científico e Tecnológico (CNPq, grant 407007/2018-0) and Fundação de Amparo à Pesquisa do Estado do Rio Grande do Sul (FAPERGS, grant 17/2551-0001073-6). VG was supported by the Government of Canada through the Ontario Research Fund (RE08-067) and the Natural Sciences and Engineering Research Council of Canada (NSERC). MP was supported by the Onassis Foundation (grant R-ZJ 003). MK was supported by Netherlands Organization for Scientific Research (NWO) Technology Foundation STW/VIDI (grant 13492). MS was supported by Ramon y Cajal Grant (RYC-2017-21814).
B signalling uncouples plant growth-defense tradeoffs. Nat Commun. 7:12570. doi: $10.1038 /$ ncomms 12570

Chung, S. H., Rosa, C., Scully, E. D., Peiffer, M., Tooker, J. F., Hoover, K., et al. (2013). Herbivore exploits orally secreted bacteria to suppress plant defenses. Proc. Natl. Acad. Sci. U.S.A. 110, 15728-15733. doi: 10.1073/pnas.13088 67110

Cruz-Miralles, J., Cabedo-López, M., Pérez-Hedo, M., Flors, V., and Jaques, J. A. (2019). Zoophytophagous mites can trigger plant-genotype specific defensive responses affecting potential prey beyond predation: the case of Euseius stipulatus and Tetranychus urticae in citrus. Pest Manag. Sci. 75, 1962-1970. doi: 10.1002/ps.5309

De Bruyne, L., Höfte, M., and De Vleesschauwer, D. (2014). Connecting growth and defense: the emerging roles of brassinosteroids and gibberellins in plant innate immunity. Mol. Plant 7, 943-959. doi: 10.1093/mp/ ssu050

Douglas, A. E. (2018). Strategies for enhanced crop resistance to insect pests. Ann. Rev. Plant Biol. 69, 637-660. doi: 10.1146/annurev-arplant-042817-040248

Erb, M. (2018). Plant defenses against herbivory: closing the fitness gap. Trends Plant Sci. 23, 187-194. doi: 10.1016/j.tplants.2017.11.005

Ferrari, S., Savatin, D. V., Sicilia, F., Gramegna, G., Cervone, F., and Lorenzo, G. D. (2013). Oligogalacturonides: plant damage-associated molecular patterns and regulators of growth and development. Front. Plant Sci. 4:49. doi: $10.3389 / \mathrm{fpls} .2013 .00049$

Finkel, O. M., Castrillo, G., Herrera Paredes, S., Salas González, I., and Dangl, J. L. (2017). Understanding and exploiting plant beneficial microbes. Curr. Opin. Plant Biol. 38, 155-163. doi: 10.1016/j.pbi.2017.04.018

Glas, J. J., Schimmel, B. C. J., Alba, J. M., Escobar-Bravo, R., Schuurink, R. C., and Kant, M. R. (2012). Plant glandular trichomes as targets for breeding 
and engineering resistance to herbivores. Int. J. Mol. Sci. 13, 17077-17103. doi: 10.3390/ijms131217077

Goggin, F. L., Lorence, A., and Topp, C. N. (2015). Applying highthroughput phenotyping to plant-insect interactions: picturing more resistant crops. Curr. Opin. Insect Sci. 9, 69-76. doi: 10.1016/j.cois.2015. 03.002

Gomes Neto, A. V., Silva, P. R. R., Melo, J. W. S., Melo Júnior, L. C., and de França, S. M. (2017). Biology and life table of Tetranychus neocaledonicus on lima bean. Int. J. Acarol. 43, 622-626. doi: 10.1080/01647954.2017.1 377288

Grbić, M., Van Leeuwen, T., Clark, R. M., Rombauts, S., Rouzé, P., Grbić, V., et al. (2011). The genome of Tetranychus urticae reveals herbivorous pest adaptations. Nature 479, 487-492. doi: 10.1038/nature10640

Guo, Q., Major, I. T., and Howe, G. A. (2018). Resolution of growth-defense conflict: mechanistic insights from jasmonate signaling. Curr. Opin. Plant Biol. 44, 72-81. doi: 10.1016/j.pbi.2018.02.009

Heidel-Fischer, H. M., and Vogel, H. (2015). Molecular mechanisms of insect adaptation to plant secondary compounds. Curr. Opin. Insect Sci. 8, 8-14. doi: 10.1016/j.cois.2015.02.004

Heinrich, M., Hettenhausen, C., Lange, T., Wünsche, H., Fang, J., Baldwin, I. T., et al. (2013). High levels of jasmonic acid antagonize the biosynthesis of gibberellins and inhibit the growth of Nicotiana attenuata stems. Plant J. 73, 591-606. doi: 10.1111/tpj.12058

Hogenhout, S. A., and Bos, J. I. B. (2011). Effector proteins that modulate plant-insect interactions. Curr. Opin. Plant Biol. 14, 422-428. doi: 10.1016/j.pbi.2011.05.003

Hörger, A. C., Fones, H. N., and Preston, G. (2013). The current status of the elemental defense hypothesis in relation to pathogens. Front. Plant Sci. 4:395. doi: $10.3389 /$ fpls.2013.00395

Hori, K. (1992). "Insect secretion and their effect on plant growth, with special reference to hemipterans," in Biology of Insect-Induced Galls, eds J. D. Shorthouse and O. Rohfristsch (New York, NY: Oxford University Press), 157-170.

Hou, X., Ding, L., and Yu, H. (2013). Crosstalk between GA and JA signaling mediates plant growth and defense. Plant Cell Rep. 32, 1067-1074. doi: 10.1007/s00299-013-1423-4

Kant, M. R., Sabelis, M. W., Haring, M. A., and Schuurink, R. C. (2008). Intraspecific variation in a generalist herbivore accounts for induction and impact of host-plant defenses. Proc. R. Soc. B Biol. Sci. 275, 443-452. doi: $10.1098 /$ rspb.2007.1277

Kloth, K. J., Thoen, M. P. M., Bouwmeester, H. J., Jongsma, M. A., and Dicke, M. (2012). Association mapping of plant resistance to insects. Trends Plant Sci. 17, 311-319. doi: 10.1016/j.tplants.2012.01.002

Koch, K. G., Chapman, K., Louis, J., Heng-Moss, T., and Sarath, G. (2016). Plant tolerance: a unique approach to control hemipteran pests. Front. Plant Sci. 7:1363. doi: 10.3389/fpls.2016.01363

Martel, C., Zhurov, V., Navarro, M., Martinez, M., Cazaux, M., Auger, P., et al. (2015). Tomato whole genome transcriptional response to Tetranychus urticae identifies divergence of spider mite-induced responses between tomato and Arabidopsis. Mol. Plant Microbe Interact. 28, 343-361. doi: 10.1094/MPMI-09-14-0291-FI

Mouden, S., Sarmiento, K. F., Klinkhamer, P. G., and Leiss, K. A. (2017). Integrated pest management in western flower thrips: past, present and future. Pest Manag. Sci. 73, 813-822. doi: 10.1002/ps.4531

Navia, D., de Mendonça, R. S., Skoracka, A., Szydło, W., Knihinicki, D., Hein, G. L., et al. (2013). Wheat curl mite, Aceria tosichella, and transmitted viruses: an expanding pest complex affecting cereal crops. Exp. Appl. Acarol. 59, 95-143. doi: 10.1007/s10493-012-9633-y

Oates, C. N., Denby, K. J., Myburg, A. A., Slippers, B., and Naidoo, S. (2016). Insect gallers and their plant hosts: from omics data to systems biology. Int. J. Mol. Sci. 17, 1891-1905. doi: 10.3390/ijms17111891

Pappas, M. L., Steppuhn, A., Geuss, D., Topalidou, N., Zografou, A., Sabelis, M. W., et al. (2015). Beyond predation: the zoophytophagous predator Macrolophus pygmaeus induces tomato resistance against spider mites. PLoS ONE 10:e0127251. doi: 10.1371/journal.pone.0127251

Pel, M. J. C., and Pieterse, C. M. J. (2013). Microbial recognition and evasion of host immunity. J. Exp. Bot. 64, 1237-1248. doi: 10.1093/jxb/ ers 262
Peterson, R. K. D., Varella, A. C., and Higley, L. G. (2017). Tolerance: the forgotten child of plant resistance. PeerJ 5:e3934. doi: 10.7717/peerj.3934

Pieterse, C. M., Zamioudis, C., Berendsen, R. L., Weller, D. M., Van Wees, S. C., and Bakker, P. A. (2014). Induced systemic resistance by beneficial microbes. Annu. Rev. Phytopathol. 52, 347-375. doi: 10.1146/annurev-phyto-082712102340

Qin, X., Liu, J. H., Zhao, W. S., Chen, X. J., Guo, Z. J., and Peng, Y. L. (2013). Gibberellin 20-oxidase gene OsGA20ox3 regulates plant stature and disease development in rice. Mol. Plant Microbe Interact. 26, 227-239. doi: 10.1094/MPMI-05-12-0138-R

Riley, D. G., Joseph, S. V., Srinivasan, R., and Diffie, S. (2011). Thrips vectors of tospoviruses. J. Integ. Pest Manag. 2, I1-I20. doi: 10.1603/IPM10020

Rioja, C., Zhurov, V., Bruinsma, K., Grbic, M., and Grbic, V. (2017). Plantherbivore interactions: a case of an extreme generalist, the Two-Spotted Spider Mite Tetranychus urticae. Mol. Plant Microbe Interact. 30, 935-945. doi: 10.1094/MPMI-07-17-0168-CR

Santamaria, M. E., Cambra, I., Martinez, M., Pozancos, C., Gonzalez-Melendi, P., Grbic, V., et al. (2012). Gene pyramiding of peptidase inhibitors enhances plant resistance to the spider mite Tetranychus urticae. PLoS ONE 7:e43011. doi: 10.1371/journal.pone.0043011

Santamaria, M. E., Gonzalez-Cabrera, J., Martinez, M., Grbic, V., Castañera, P., Diaz, I., et al. (2015). Digestive proteases in bodies and faeces of the two-spotted spider mite, Tetranychus urticae. J. Insect Physiol. 78, 69-77. doi: 10.1016/j.jinsphys.2015.05.002

Scheirs, J., Vandevyvere, I., Wollaert, K., Blust, R., and De Bruyn, L. (2006). Plant-mediated effects of heavy metal pollution on host choice of a grass miner. Environ. Pollut. 143, 138-145. doi: 10.1016/j.envpol.200 5.11 .001

Skoracka, A., Smith, L., Oldfield, G., Cristofaro, M., and Amrine, J. W. J. (2010). Host-plant specificity and specialization in eriophyoid mites and their importance for the use of eriophyoid mites as biocontrol agents of weeds. Exp. Appl. Acarol. 51, 93-113. doi: 10.1007/978-90-481-9562-6_6

Ssemwogerere, C., Ochwo-Ssemakula, M., Kovach, J., Kyamanywa, S., and Karungi, J. (2013). Species composition and occurrence of thrips on tomato and pepper as influenced by farmers' management practices in Uganda. J. Plant Prot. Res. 53, 158-164. doi: 10.2478/jppr-2013-0024

Steenbergen, M., Abd-El-Haliem, A., Bleeker, P., Dicke, M., Escobar-Bravo, R., Cheng, G., et al. (2018). Thrips advisor: exploiting thrips-induced defences to combat pests on crops. J. Exp. Bot. 69, 1837-1848. doi: 10.1093/jxb/ ery060

Stenger, D. C., Hein, G. L., Tatineni, S., and French, R. (2016). "Eriophyid mite vectors of plant viruses," in Vector-Mediated Transmission of Plant Pathogens, ed J. K. Brown (St. Paul, MN: APS Publication), 263-274. doi: 10.1094/9780890545355.018

Su, Q., Oliver, K. M., Xie, W., Wu, Q., Wang, S., Zhang, Y., et al. (2015). The whitefly-associated facultative symbiont Hamiltonella defensa suppresses induced plant defences in tomato. Funct. Ecol. 29, 1007-1018. doi: 10.1111/1365-2435.12405

Urbaneja-Bernat, P., Ibáñez-Gual, V., Montserrat, M., Aguilar-Fenollosa, E., and Jaques, J. A. (2019). Can interactions among predators alter the natural regulation of an herbivore in a climate change scenario? The case of Tetranychus urticae and its predators in citrus. J. Pest Sci. 92:1149. doi: 10.1007/s10340-019-01114-8

Villarroel, C. A., Jonckheere, W., Alba, J. M., Glas, J. J., Dermauw, W., Haring, M. A., et al. (2016). Salivary proteins of spider mites suppress defenses in Nicotiana benthamiana and promote mite reproduction. Plant J. 86, 119-131. doi: $10.1111 /$ tpj.13152

Wang, F., Ning, D., Chen, Y., Dang, C., Han, N. S., Liu, Y., et al. (2015). Comparing gene expression profiles between $\mathrm{Bt}$ and non-Bt rice in response to brown planthopper infestation. Front. Plant Sci. 6:1181. doi: 10.3389/fpls.2015.01181

Wang, W., Vinocur, B., and Altman, A. (2003). Plant responses to drought, salinity and extreme temperatures: towards genetic engineering for stress tolerance. Planta 218, 1-14. doi: 10.1007/s00425-003-1105-5

Wu, S., Tang, L., Zhang, X., Xing, Z., Lei, Z., and Gao, Y. (2018). A decade of a thrips invasion in China: lessons learned. Ecotoxicology 27, 1032-1038. doi: 10.1007/s10646-017-1864-6

Ximenez-Embún, M. G., Castañera, P., and Ortego, F. (2017). Drought stress in tomato increases the performance of adapted and 
non-adapted strains of Tetranychus urticae. J. Insect Physiol. 96, 73-81. doi: 10.1016/j.jinsphys.2016.10.015

Zhang, N. X., Messelink, G. J., Alba, J. M., Schuurink, R. C., Kant, M. R., and Janssen, A. (2018). Phytophagy of omnivorous predator Macrolophus pygmaeus affects performance of herbivores through induced plant defences. Oecologia 186, 101-113. doi: 10.1007/s00442-0174000-7

Zhurov, V., Navarro, M., Bruinsma, K. A., Arbona, V., Santamaria, M. E., Cazaux, M., et al. (2014). Reciprocal responses in the interaction between Arabidopsis and the cell-content-feeding chelicerate herbivore spider mite. Plant Physiol. 164, 384-399. doi: 10.1104/pp.113.231555
Conflict of Interest Statement: The authors declare that the research was conducted in the absence of any commercial or financial relationships that could be construed as a potential conflict of interest.

Copyright $\odot 2019$ Sperotto, Grbic, Pappas, Leiss, Kant, Wilson, Santamaria and Gao. This is an open-access article distributed under the terms of the Creative Commons Attribution License (CC BY). The use, distribution or reproduction in other forums is permitted, provided the original author(s) and the copyright owner(s) are credited and that the original publication in this journal is cited, in accordance with accepted academic practice. No use, distribution or reproduction is permitted which does not comply with these terms. 